\title{
Comparative study on antidiabetic, cytotoxicity, antioxidant and antibacterial properties of biosynthesized silver nanoparticles using outer peels of two varieties of Ipomoea batatas (L.) Lam
}

This article was published in the following Dove Press journal: International Journal of Nanomedicine

\author{
Gitishree Das' \\ Jayanta Kumar Patra' \\ Nagaraj Basavegowda ${ }^{2}$ \\ Chethala N Vishnuprasad ${ }^{3}$ \\ Han-Seung Shin ${ }^{4}$ \\ 'Research Institute of Biotechnology \& \\ Medical Converged Science, Dongguk \\ University, Seoul, Gyeonggi-do 10326, \\ Republic of Korea; ${ }^{2}$ Department of \\ Biotechnology, Yeungnam University, \\ Gyeongsan, Republic of Korea; ${ }^{3}$ Centre \\ for Ayurveda Biology and Holistic \\ Nutrition, The University of Trans- \\ Disciplinary Health Sciences and \\ Technology (TDU), Bengaluru 560064, \\ India; ${ }^{4}$ Department of Food Science and \\ Biotechnology, Dongguk University, \\ Seoul, Gyeonggi-do 10326, Republic of \\ Korea
}

Background: Ipomoea batatas (L.) Lam.(Ib) has high content of various beneficial nutrients which helps in improving and maintaining human health. It is well known as a functional food and also a valuable source of unique natural products. It contains various phenolic and flavonoid bioactive compounds.

Methods: In this study, using the outer peel of two varieties of $\mathrm{Ib}$ : Korean red skin sweet potato and Korean pumpkin sweet potato, silver nanoparticles (AgNPs) were synthesized (termed Ib1AgNps and Ib2-AgNps), respectively. Characterization of Ib1-AgNPs and Ib2-AgNPs was carried out through scanning electron microscopy, Fourier-transform infrared (FT-IR) spectroscopy, energy-dispersive X-ray analysis, X-ray powder diffraction and UV-Vis spectroscopy. Further, the bio-potential of the synthesized AgNPs was investigated by antidiabetic ( $\alpha$-glucosidase assay), antioxidant (free radical scavenging assays), antibacterial (disc diffusion method) and cytotoxicity assays (cell viability against HepG2 cells).

Results: FT-IR spectroscopy revealed the contribution of bioactive compounds existing in Ib1 and $\mathrm{Ib} 2$ extracts, in the biosynthesis and equilibrium of the AgNPs. Although the Ib2-AgNPs had a higher atomic percentage of $\mathrm{Ag}$ in comparison with Ib1-AgNPs, in the antidiabetic assay, the inhibition percentage of $\alpha$-glucosidase was higher for AgNPs of Ib1 than Ib2, at all three concentrations examined. From the cytotoxicity results, HepG2 cancer cells were more sensitive to the Ib1AgNPs in comparison to the Ib2-AgNPs-treated HepG2 cells. The antioxidant prospective was higher in Ib2-AgNPs than Ib1-AgNPs. Moreover, the Ib2-AgNPs showed inhibitory action against all five tested pathogenic bacteria, producing an inhibition zone of 8.74-11.52 mm while Ib1AgNPs had an inhibitory effect on four of them, with an 8.67-11.23 (mm) inhibition zone.

Conclusions: Overall, the results concluded that the Ib2-AgNPs exhibited relatively higher functional activity than Ib1-AgNPs, which might be credited to the greater abundance of bioactive compounds existing in Ib2 extract that acted as reducing as well as capping agents in the synthesis of Ib2-AgNPs. Overall, the current study highlights a novel cost-effective and eco-friendly AgNPs synthesis using food waste peels with biocompatibility and could be potentially utilized in biomedical and pharmaceutical industries.

Keywords: antidiabetic, antibacterial, antioxidant, cytotoxicity, silver nanoparticles, Ipomoea batatas

\section{Introduction}

In the mission intended for green and eco-friendly ways of synthesizing nanomaterials for the development of new products, plant biomasses have proven useful in
Correspondence: Han-Seung Shin Department of Food Science \& Biotechnology, Dongguk UniversityBiomed Campus, 32, Dongguk-ro, Ilsandong-gu, Goyang-si, Gyeonggi-do

10326, South Korea

Tel +8 2319615184

Email spartan@dongguk.edu
International Journal of Nanomedicine 2019:14 474I-4754

4741

bmit your manuscrip

DovePress $f$ in $\boldsymbol{v}$

httr://doi.org/10.21474IN S210517 
the manufacture of sustainable nanoparticles (NPs), ${ }^{1,2}$ which are frequently used in biological approaches. ${ }^{3}$ Due to their unique properties and prospective applications, bio-synthesis of silver nanoparticles (AgNPs) has received considerable attention in current centuries. ${ }^{4}$ NPs with controllable shapes and sizes have usually been synthesized by means of chemical or physical methods. ${ }^{5}$ However, usage of toxic chemicals and expensive physical procedures and tools ${ }^{6}$ has led to the emergence of environmentally friendly approaches. NPs synthesized through natural sources are the nontoxic, recyclable and most effective technique which is a harmless and nontoxic alternative. ${ }^{7}$ As per to a study of collected works and literature, naturally existing organic foodstuff and agronomic unwanted resources have not yet been broadly studied for the synthesis of several kinds of NPs. ${ }^{5}$

AgNPs amongst other metal NPs have intense application in the pharmaceutical fields. It has a unique thermal, electrical and optical properties which gives it great significance to use. ${ }^{8}$ It has reported earlier that AgNPs retains excellent anticancer, antiviral, antimicrobial and antiinflammatory potential with enhanced bio-degradability and less toxicity. ${ }^{8,9}$ Bio-synthesis of silver NPs is economic and environmentally safe approach. ${ }^{10}$

Ipomoea batatas $(\mathrm{Ib})$ or sweet potato is the sixth most significant food crop worldwide and is an extremely versatile and delicious vegetable. ${ }^{11-13}$ Ipomoea batatas comprises high contents of various nutrients and phytochemicals that are beneficial for improving and maintaining human health. ${ }^{11,14}$ Currently $\mathrm{Ib}$ is well known as a valuable source of exclusive natural bioactive compounds and for its high nutritional value, ${ }^{15,16}$ counting few of which can be utilized in the development of medicines against various diseases and also in the making of manufacturing products. ${ }^{12} \mathrm{lb}$ plant also has abundant therapeutic significance as an imminent antidiabetic, antiinflammatory and anticancer agent. ${ }^{12,14,17}$

The essential primary metabolites like organic acids, amino acids, sugars, sugar alcohols and health beneficial phytochemicals including phenolic acids, flavonoids, anthocyanins and carotenoids and hydrophilic primary metabolites were identified in colored flesh $\mathrm{Ib}$ such as white orange and purple in an earlier study. ${ }^{17}$ As per the previous study, carotenoids like $\alpha$-carotene, $\beta$-carotene, zeaxanthin and lutein were identified in white-fleshed Ib. ${ }^{17}$ Furthermore, it was also reported that orange-fleshed Ib contains the highest level and white-fleshed Ib contains the lowest level of carotenoid. ${ }^{17}$ Purple Ib was reported to have various phenolic compounds, and most of them were found to be anthocyanins. ${ }^{18}$ Hence, Ib is recognized as a basis of unique and valuable active compounds that can be exploited in the improvement of natural drugs against several diseases. ${ }^{12}$ It acts as a vital source in the production of sugar, alcohol and starch in the field of food manufacturing. The high cost for the right process of discarding the wastes generated from these processes is the foremost cause of loss in the field of food manufacturing. ${ }^{11}$ Recently. public concerns about food waste and its economic impact on social life are improved to develop research strategies which can promote food waste utilization in an effective way. ${ }^{19}$ Consequently, the discovery of new techniques to recycle agro-waste materials efficiently is essential.

Therefore, it is of great curiosity to get benefit of this excellent vegetable peel to bio-synthesize AgNPs as a new therapeutic agent. The current study aimed at the green synthesis of AgNPs using the outer peel waste of two Korean sweet potato (Ib) varieties, Korean red skin sweet potato and Korean pumpkin sweet potato, which have are termed as Ib1 and Ib2, respectively. Following the bio-synthesis of the AgNPs from these two sweet potato varieties, their antidiabetic, cytotoxicity, antioxidant and antibacterial actions were compared.

\section{Materials and methods Preparation of extract of $\mathrm{lb}$ waste peel}

Two varieties of $\mathrm{Ib}$ (sweet potato), Korean name bamgoguma (Ib1) and Korean name hobak-goguma (Ib2), were purchased from the market in Goyang, Republic of Korea (Figure 1A and B). The sweet potatoes were washed thoroughly with double-distilled water $\left(\mathrm{DDH}_{2} \mathrm{O}\right)$, dried and the unwanted outer nonedible parts were peeled off and cut into small portions. Aliquots $(220 \mathrm{~g})$ of the cut peels were retained in separate Erlenmeyer flasks (1000 $\mathrm{mL}$ ) containing $550 \mathrm{~mL} \mathrm{DDH}_{2} \mathrm{O}$. The mixtures were boiled under constant stirring and then cooled to room temperature and stored at $4^{\circ} \mathrm{C}$ for further use.

\section{Biosynthesis of AgNPs using outer peel of $\mathrm{Ib}$ ( $\mathrm{IbI}$ and $\mathrm{lb} 2$ )}

Ib1-AgNPs and Ib2-AgNPs were biosynthesized under laboratory conditions. Briefly, separate solutions of the $\mathrm{Ib} 1$ and $\mathrm{Ib} 2$ extracts were prepared by placing $100 \mathrm{~mL}$ of aqueous $1 \mathrm{mM} \mathrm{AgNO}_{3}$ in an Erlenmeyer flask $(500 \mathrm{~mL}$ volume) and adding $10 \mathrm{~mL}$ of extract (Ib1 and $\mathrm{Ib} 2$, 

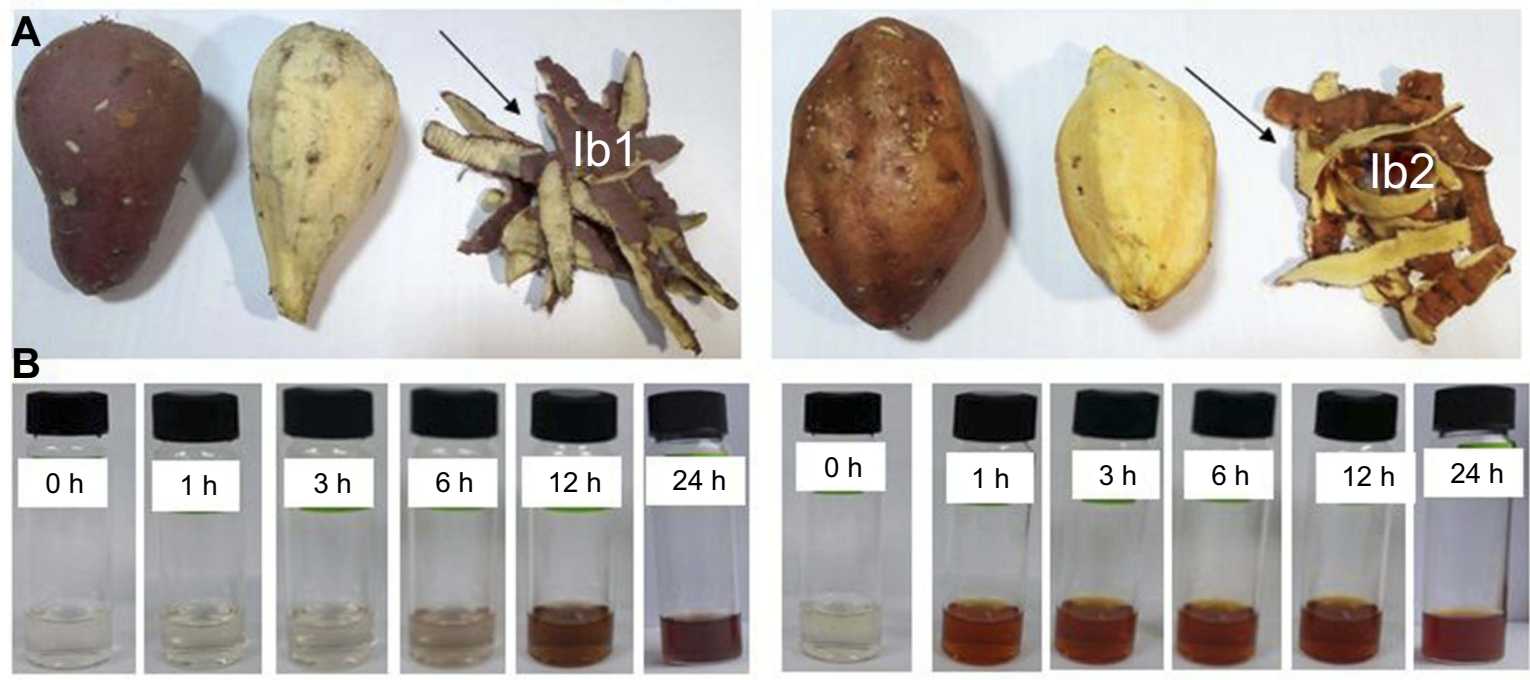

C
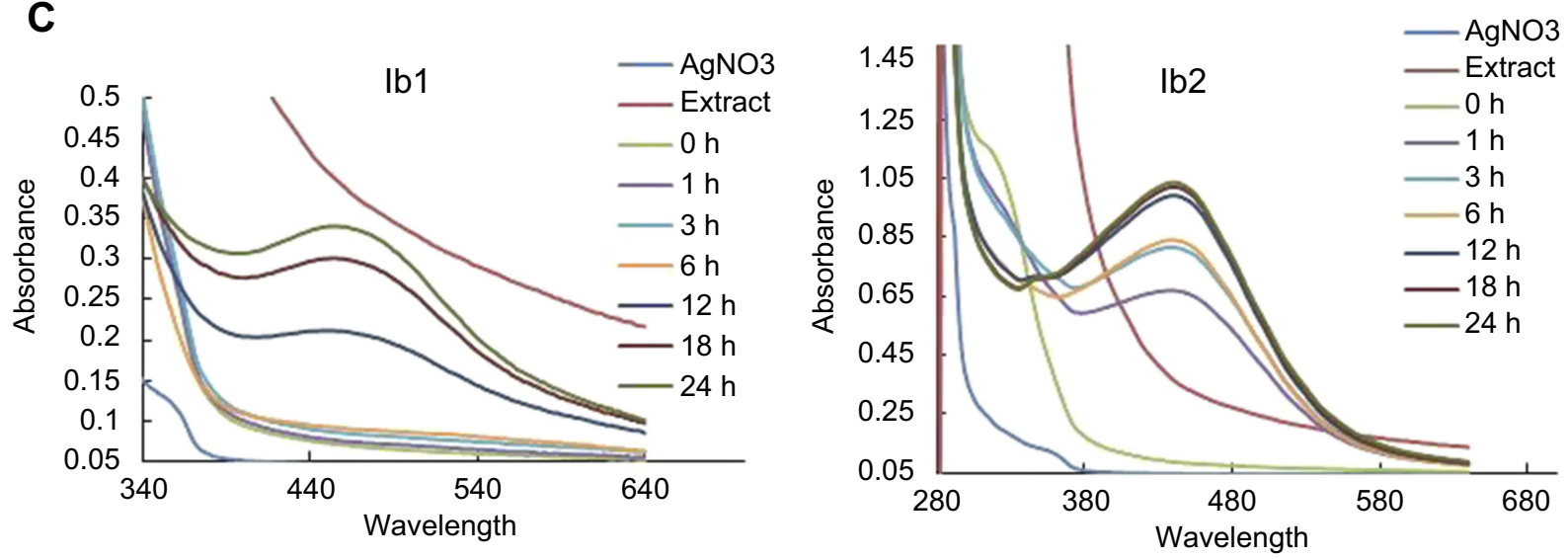

Figure I (A) Sweet potato (Ipomoea batatas) varieties Korean red skin (IbI) and Korean pumpkin (Ib2) vegetable and waste part. (B) Gradual color transition of lb extract during synthesis of $\mathrm{IbI}-\mathrm{AgNPs}$ and $\mathrm{Ib} 2-\mathrm{AgNPs}$ between 0 and $24 \mathrm{hrs}$. (C) UV-Vis spectra of the biosynthesized IbI-AgNPs and Ib2-AgNPs under laboratory condition.

respectively) dropwise with continuous stirring at room temperature. $^{20}$ The green synthesis of Ib1-AgNPs and Ib2-AgNPs was monitored by the gradual change in the color of the reaction solutions at regular time intervals. After the final and complete synthesis, each reaction solution was centrifuged (at 10,000 rpm, 30 mins). The pellets were washed properly with $\mathrm{DDH}_{2} \mathrm{O}$ and again centrifuged. Finally, the pellets were dehydrated at $55^{\circ} \mathrm{C}$ and put in storage in a vial for future study.

\section{Characterization of biosynthesized lb I- AgNPs and lb2-AgNPs}

The Ib1-AgNPs and Ib2-AgNPs were characterized by means of UV-Vis spectroscopy, X-ray powder diffraction (XRD), field emission-scanning election microscopy (SEM), energy-dispersive X-ray spectroscopy (EDX) and
Fourier-transform infrared (FT-IR) analyses using specific instruments, and standard procedures are as described in details in the previous publications. ${ }^{21,22}$

\section{Antidiabetic action of bio-synthesized $\mathrm{lbl}$-AgNPs and lb2-AgNPs}

The $\alpha$-glucosidase enzyme from Saccharomyces cerevisiae ( $\geq 30 \mathrm{U} / \mathrm{mg}$; Cat. No. G5003), and other chemicals were obtained from Sigma-Aldrich, St. Louis, MI, USA. The Ib1-AgNPs and Ib2-AgNPs samples were liquefied in methanol at $10 \mathrm{mg} / \mathrm{mL}$ with the assistance of a sonicator water bath. The $\alpha$-glucosidase inhibition assay was accomplished by the standard procedure. ${ }^{23}$ In total, $10 \mu \mathrm{g} / \mathrm{mL}$ of the test samples were aliquoted into 96-well plates and diluted with $0.02 \mathrm{M}$ sodium phosphate buffer ( $\mathrm{pH}$ 6.9), successively. To the final volume $(50 \mu \mathrm{L}), 50 \mu \mathrm{L}$ of $\alpha$ - 
glucosidase $(0.5 \mathrm{U} / \mathrm{mL})$ was added. After keeping for 10 mins at room temperature, $50 \mu \mathrm{L}$ of $p$-nitrophenyl- glucopyranoside $(3.0 \mathrm{mM})$ was added as the substrate and the reaction solutions further incubated at $37^{\circ} \mathrm{C}$ for 20 mins. Next, $50 \mu \mathrm{L}$ of $\mathrm{Na}_{2} \mathrm{CO}_{3}(0.1 \mathrm{M})$ was added, and the reaction was at stationary phase. Absorbance was documented through a plate reader at $405 \mathrm{~nm}$ wavelength. The plate also contained the positive standard (enzyme, buffer, and substrate). The inhibition percentage of $\alpha$-glucosidase action was evaluated as follows:

$$
\% \text { Inhibition }=\left[\frac{\mathrm{Abs}_{\text {Control }}-\mathrm{Abs}_{\text {Test }}}{\mathrm{Abs}_{\text {Control }}}\right] \times 100
$$

\section{Antibacterial action of biosynthesized $\mathrm{lb} \mathrm{I}-\mathrm{AgNPs}$ and $\mathrm{lb} 2-\mathrm{AgNPs}$}

The biosynthesized Ib1-AgNPs and Ib2-AgNPs were separately tested for their antibacterial effect against five pathogenic bacteria, including E. faecium DB01, S. enteritisca KCCM 11806, L. monocytogenes ATCC 19111, B. cereus KCTC 3624 and $S$. aureus ATCC 13565, by following the standard disc diffusion technique with trivial modification. ${ }^{24,25}$

\section{Antioxidant potential of biosynthesized $\mathrm{lb} \mathrm{I}-\mathrm{AgNPs}$ and $\mathrm{lb} 2-\mathrm{AgNPs}$}

The biosynthesized Ib1-AgNPs and Ib2-AgNPs were, respectively, examined for their antioxidant activity by the ABTS, DPPH and NOx radical scavenging analyses, and reducing power assay, as detailed by Patra et $\mathrm{al}^{5}$

\section{Cytotoxicity activity of biosynthesized $\mathrm{lb} \mathrm{l}-\mathrm{AgNPs}$ and $\mathrm{lb} 2-\mathrm{AgNPs}$}

The biosynthesized Ib1-AgNPs and Ib2-AgNPs were dissolved separately in Dulbecco's phosphate-buffered saline (Welgene, Gyeongsan-si, Gyeongsangbuk-do, Republic of Korea) at $1 \mathrm{mg} / \mathrm{mL}$ and sterilized through an $0.22 \mu \mathrm{m}$ syringe filter (Millipore, Billerica, MA, USA). For treating HepG2 cells, the Ib1-AgNPs and Ib2-AgNPs were prepared separately at different concentrations $(0.1,0.01$, $0.001,0.0001,0.00001 \mathrm{mg} / \mathrm{mL}$ ) usingDMEM (Welgene) supplemented with $10 \%(\mathrm{v} / \mathrm{v})$ fetal bovine serum and $1 \%$ penicillin-streptomycin (Gibco, Carlsbad, CA, USA) ${ }^{26}$

The HepG2 cells were acquired from a cell line bank (Seoul, Republic of Korea) and cultured in complete DMEM in a $\mathrm{CO}_{2}(5 \%)$ humidified incubator (maintained at $37^{\circ} \mathrm{C}$ ). The harvested, completely grown cells were trypsinized with trypsin-EDTA (Gibco) and transferred to 96 -well plates $\left(100 \mu \mathrm{L} /\right.$ well, with $5 \times 10^{4}$ cells per well). The HepG2 cells viability was evaluated by the trypan blue exclusion test, and the cells were kept in a humidified incubator at $37^{\circ} \mathrm{C}$ with $5 \% \mathrm{CO}_{2}$ and $95 \%$ air for $24 \mathrm{hrs}$. The medium was removed after $24 \mathrm{~h}$ incubation, and the cells were inoculated to $0.001,0.010,0.100$ and $1.000 \mathrm{mg} / \mathrm{mL} \mathrm{Ib} 1-A g N P s$ and Ib2-AgNPs, which were distributed in DMEM. Again, the cells were kept for incubation under $5 \% \mathrm{CO}_{2}$ at $37^{\circ} \mathrm{C}(24 \mathrm{~h}-) .{ }^{26}$

The cell cytotoxicity action of bio-synthesized Ib1AgNPs and Ib2-AgNPs was evaluated by means of an EZ-Cytox Kit (DoGenBio Co., Ltd., Seoul, Republic of Korea) according to the manufacturer's procedure. The morphology and viability of cells exposed to Ib1-AgNPs and Ib2-AgNPs were evaluated by the trypan blue exclusion test. ${ }^{26}$

\section{Statistical analysis}

Data are represented by means of the mean \pm standard deviation. One-way ANOVA was performed, followed by Duncan's test (at 5\% level of significance) using SPSS version 23.0 software (IBM Corp., Armonk, NY, USA).

\section{Results}

\section{Biosynthesis of AgNPs using $\mathrm{lbl}$ and $\mathrm{lb} 2$ outer peel extract}

In this study, Ib1-AgNPs and Ib2-AgNPs were synthesized under normal laboratory light using the outer peel extracts (which is typically a food waste) of two diverse varieties of $\mathrm{Ib}$ (Figure 1A). Biosynthesis of Ib1-AgNPs (Figure 1B) and Ib2-AgNPs (Figure 1B) progressed under the laboratory condition, which was visualized by the gradual change in the color of the reaction solution from without color to reddish-brown. The Ib2-AgNPs synthesis was rapid, starting within an hour, whereas the Ib1-AgNPs synthesis was slow, beginning slightly at $6 \mathrm{hrs}$ and becoming rapid after $12 \mathrm{~h}$ of reaction (Figure 1B).

\section{Characterization of biosynthesized lb I-} AgNPs and $\mathrm{lb} 2-\mathrm{AgNPs}$

Once the bio-synthesis of Ib1-AgNPs and Ib2-AgNPs was visually confirmed by the gradual color change of the reaction mixtures, the samples were categorized through UV-Vis spectroscopy, FT-IR spectroscopy, SEM, EDX and $\mathrm{XRD}$. The UV-Vis spectra of both Ib1 and Ib2 reaction 
mixtures were recorded at altered time intervals for up to $24 \mathrm{hrs}$. The highest absorbance peaks of the solution mixtures occurred at 452 and $442 \mathrm{~nm}$ for $\mathrm{Ib} 1$ and $\mathrm{Ib} 2$, respectively (Figure 1C).

The FT-IR results of extracts (Ib1 and Ib2) and their corresponding AgNPs are presented in Figure 2. The absorption peaks appeared at 3321.40, 2118.56, 1634.03, 1089.17 and $685.71 \mathrm{~cm}^{-1}$ for the Ib1 extract and at 3285.56, 2924.08, 1620.66, 1362.15, 1017.54 and 571.70 $\mathrm{cm}^{-1}$ meant for the Ib1-AgNPs (Figure 2A and B). For Ib2 extract, the absorption peaks occurred at $3315.75,2358.00$, $1862.16,1634.03,1087.29$ and $680.06 \mathrm{~cm}^{-1}$, and the corresponding shifts for the Ib2-AgNPs were observed at 3275.54, 2924.71, 1630.42, 1364.69, 1018.51, 925.01 and $519.89 \mathrm{~cm}^{-1}$ (Figure 2C and D).

Considering the UV-Vis spectra and FT-IR results, the Ib1-AgNPs and Ib2-AgNPs were confirmed to be extremely stable and further analyzed by SEM-EDX for their morphology and chemical composition. The external morphology of the Ib1-AgNPs and Ib2-AgNPs was agglomerated in nature (Figure $3 \mathrm{~A}$ and $\mathrm{B}$ ). For both the
Ib1-AgNPs and Ib2-AgNPs, the EDX results (Figure 3C and D) displayed a high peak at $3 \mathrm{keV}$, conforming to the $\mathrm{Ag}$ region, thereby identifying the existence of AgNPs in both $\mathrm{Ib} 1$ and $\mathrm{Ib} 2$. In Ib1-AgNPs, the $\mathrm{Ag}$ element accounted for $22.45 \%$ of the total composition and the corresponding content in the Ib2-AgNPs was $34.92 \%$ (Figure $3 \mathrm{C}$ and $\mathrm{D}$ ). The spectral signals for other elements, like oxygen and chlorine, were also noted in the AgNPs, amounting to $7.60 \%$ and $11.37 \%$ in the Ib1AgNPs, and $13.66 \%$ and $10.40 \%$ in the Ib2-AgNPs, respectively (Figure $3 \mathrm{C}$ and $\mathrm{D}$ ).

The XRD pattern of the biosynthesized Ib1-AgNPs and Ib2-AgNPs is shown in Figure 4. Three well-resolved diffraction peaks were apparent in Ib1-AgNPs, with peaks $(2 \theta$ angles) at $38.43^{\circ}, 46.23^{\circ}$ and $76.91^{\circ}$, equivalent to (111), (200) and (311), respectively, along with a few unknown peaks at $32.18^{\circ}, 54.92^{\circ}$ and $57.60^{\circ}$. For the Ib2-AgNPs, there were four well-resolved diffraction peaks ( $2 \theta$ angles) at $38.22^{\circ}, 46.23^{\circ}, 64.69^{\circ}$ and $76.99^{\circ}$, corresponding to (111), (200), (220) and (311), respectively, besides some unknown signals at $32.29^{\circ}$ and $43.27^{\circ}$ (Figure 4 ).
A

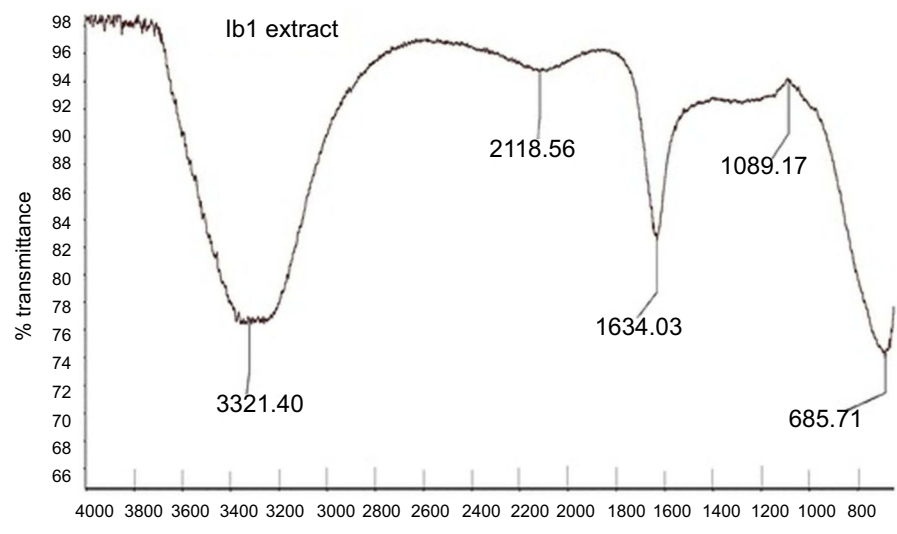

B

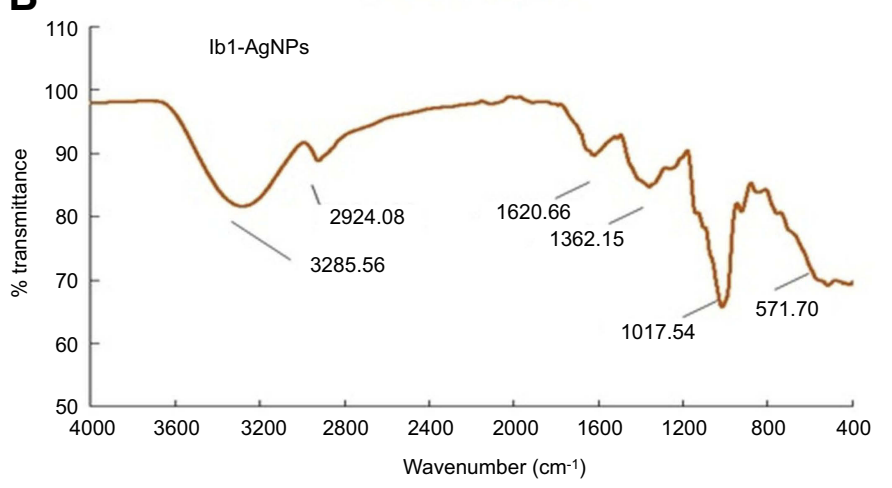

C
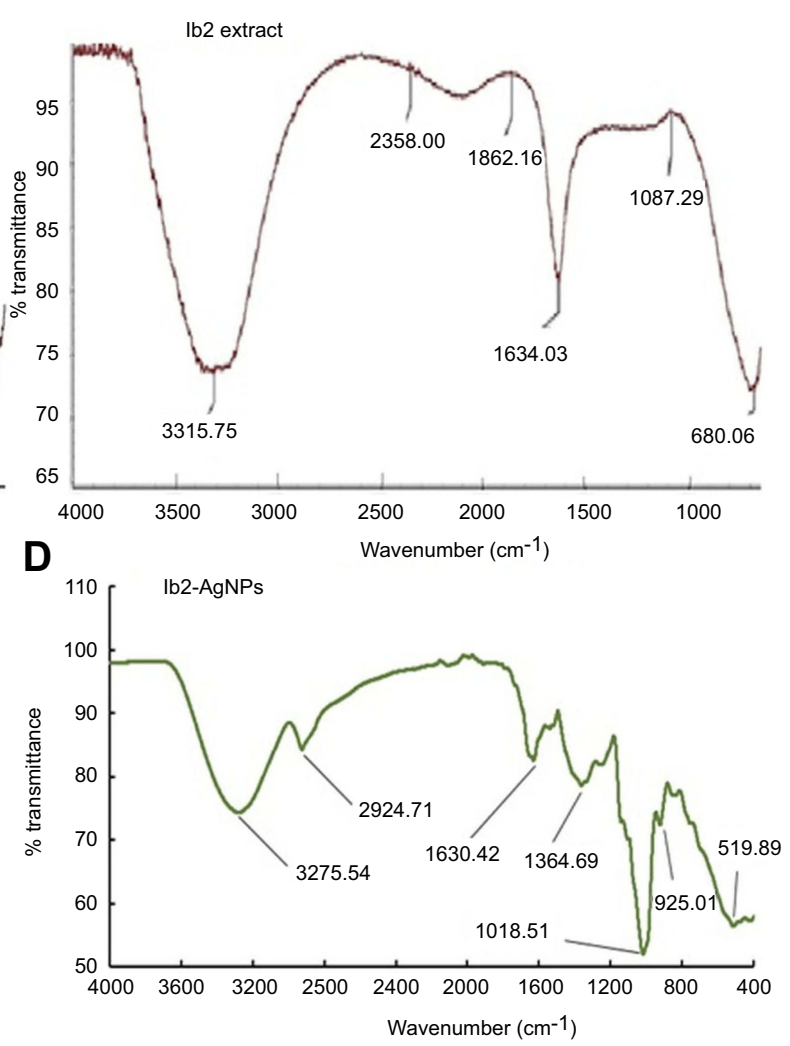

Figure 2 FT-IR spectra of $\mathrm{lbl}-\mathrm{AgNPs}(\mathbf{A}, \mathbf{B})$ and $\mathrm{lb2}-\mathrm{AgNPs}(\mathbf{C}, \mathbf{D})$. 

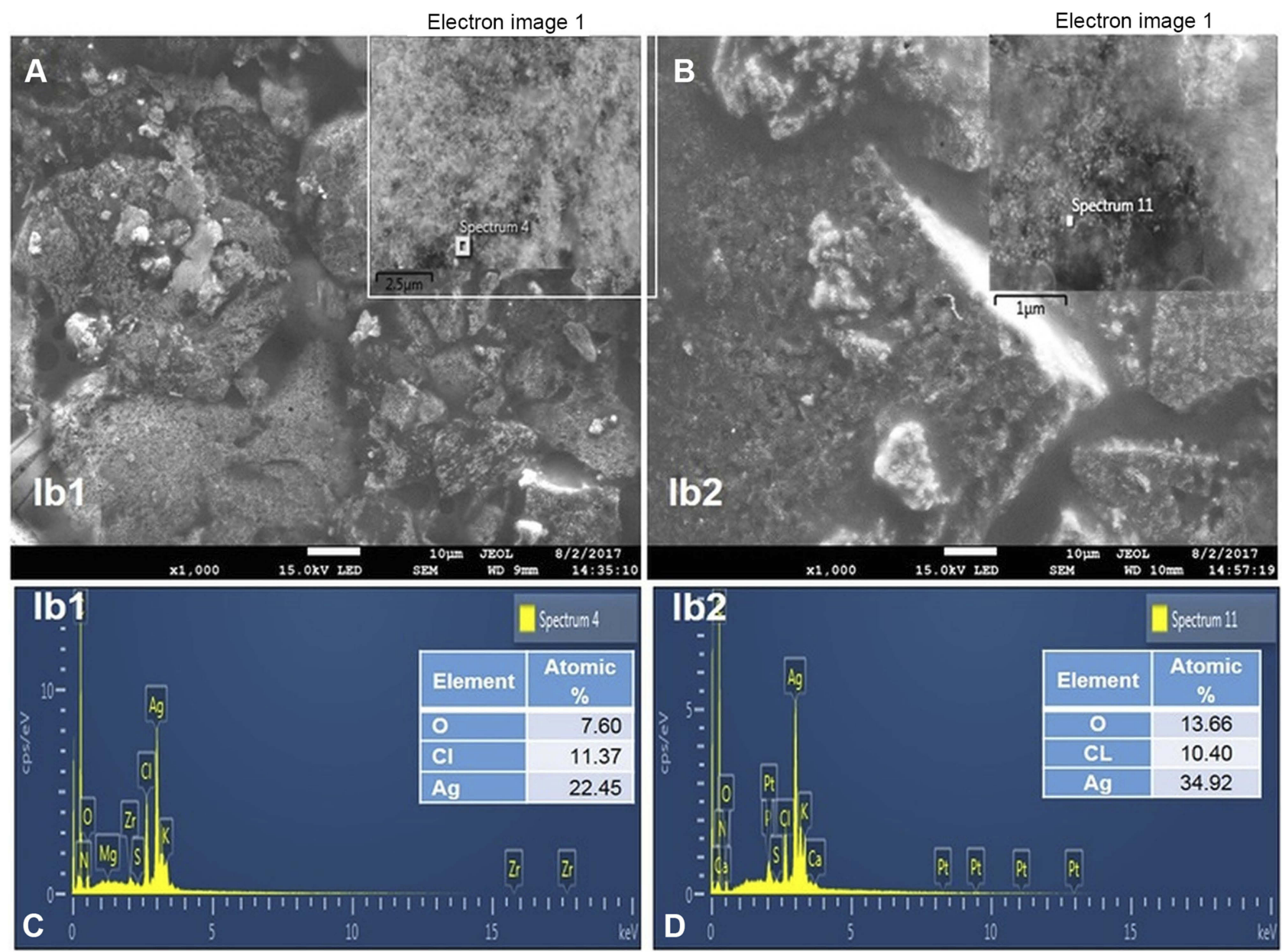

Figure 3 SEM images (A, B) and EDX data (C, D) of Ibl-AgNPs and lb2-AgNPs.

$\mathrm{lb} 1$

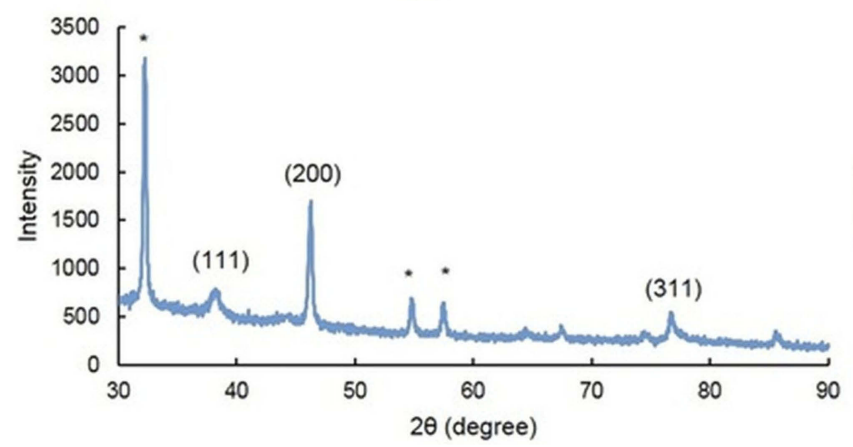

Figure 4 XRD patterns of the biosynthesized $\mathrm{lbl}$-AgNPs and lb2-AgNPs.

\section{Potential of the biosynthesized lbl- $\mathrm{AgNPs}$ and lb2-AgNPs}

Both of the biosynthesized Ib1-AgNPs and Ib2-AgNPs were evaluated for their possible antidiabetic, antibacterial, cytotoxic and antioxidant activities. lb2

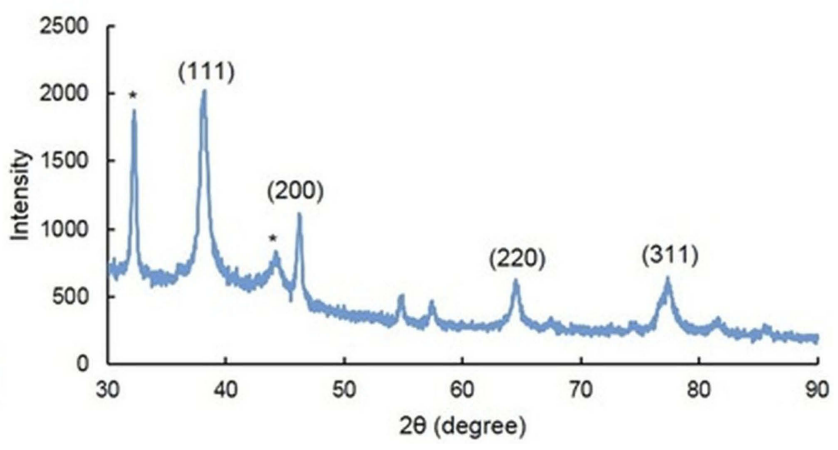

The $\alpha$-glucosidase inhibition effects of both AgNPs indicated their promising antidiabetic potential (Figure 5). The Ib1-AgNPs were highly effective and had the highest $\alpha$-glucosidase inhibition percentage, displaying 3.2\%,70.10\% and $97.73 \%$ inhibition, respectively, at the three concentrations 


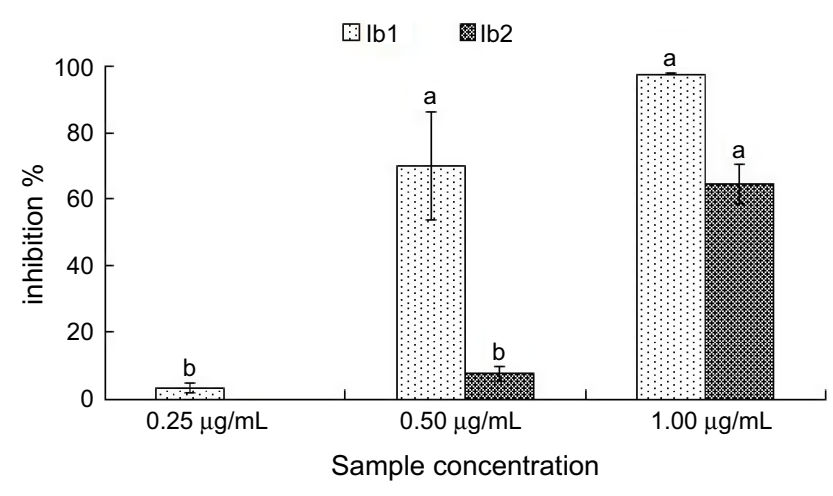

Figure $5 \boldsymbol{\alpha}$-Glucosidase activity of lbl-AgNPs and lb2-AgNPs.

tested $(0.25,0.50$ and $1.00 \mu \mathrm{g} / \mathrm{mL})$. In comparison, the $\mathrm{Ib} 2-$ AgNPs showed zero (at $0.25 \mu \mathrm{g} / \mathrm{mL}$ ), $7.4 \%$ (at $0.5 \mu \mathrm{g} / \mathrm{mL}$ ) and $64.81 \%$ inhibition (at $1.00 \mu \mathrm{g} / \mathrm{mL}$ ). Further, the $\mathrm{IC}_{50}$ values were also calculated and presented in Table 1 . The $\mathrm{IC}_{50}$ values of Ib1-AgNPs and Ib2-AgNPs were found out to be 0.36 and $0.77 \mu \mathrm{g} / \mathrm{mL}$, respectively.

The cytotoxicity of the Ib1-AgNPs and Ib2-AgNPs in $\mathrm{HepG}_{2}$ cancer cells (after $24 \mathrm{~h}$ of exposure) (Figure 6A) indicated that the cell-line viability increased with decreasing concentration in the reaction medium of the Ib1AgNPs and Ib2-AgNPs. Likewise, while detected under an inverted microscope, it was visualized that the control cells presented a higher number of well-attached live cells than the AgNPs-treated HepG2 cells (Figure 6B). Both AgNPs were extremely toxic to HepG2 cells at a higher concentration (Figure 6C and D). Significant variation in morphology due to cell death, along with limited scattering patterns and a higher number of dead cells (black arrow) were observed at the upper concentrations of the AgNPs (Figure 6C and D), whereas, consistent morphology and well-attached cells (white arrow) were seen at a lower concentration of the AgNPs (Figure 6C and D).

The antioxidant prospective of the bio-synthesized Ib1AgNPs and Ib2-AgNPs was examined by the 2,2'-azino-bis (3-ethylbenzothiazoline-6-sulfonic acid) (ABTS) and 1,1diphenyl-2-picrylhydrazyl (DPPH) scavenging analyses, nitrite/nitrate oxide (NOx) assay and reducing power test, all at three concentrations $(25,50$ and $100 \mu \mathrm{g} / \mathrm{mL})$, and the end results are shown in Figure 7. The ABTS scavenging activity of Ib1-AgNPs was $3.98-8.83 \%$ and $4.18-12.28 \%$ in the case of Ib2-AgNPs. These values were lower than the synthetic antioxidant tertiary butyl-hydroquinone (BHQ; control), which were in between the range of $17.06-73.79 \%$ at the same concentrations (Figure 7A). The DPPH scavenging potentials were 26.30-41.62\% (Ib1-AgNPs), 29.92-46.53\% (Ib2-AgNPs) and 82.61-85.68\% (BHQ) (Figure 7B). The reducing powers of BHQ, Ib1-AgNPs and Ib2-AgNPs were 0.3573-0.6210, $0.0594-0.0715$ and $0.0598-0.0852$, respectively (Figure 7C). The NOx results for the Ib1-AgNPs and Ib2-AgNPs were 4.310.16 and 5.53-12.94\%, respectively, and 17.06-73.79 for the synthetic antioxidant BHQ at the same three concentrations (Figure 7D). Further, the $\mathrm{IC}_{50}$ values of all the antioxidant assays were calculated and presented in Table 1 .

The antibacterial effect of Ib1-AgNPs and Ib2-AgNPs was tested against five pathogenic foodborne bacteria (Staphylococcus aureus ATCC 13565, Salmonella enteritica KCCM 11806, Bacillus cereus KCTC 3624, Listeria monocytogenes ATCC 19111 and Enterococcus faecium DB01). For Ib1-AgNPs, the inhibition zone was in between the range of $8.67-11.23 \mathrm{~mm}$ against the four pathogenic bacteria tested and the corresponding range for the Ib2-AgNPs was $8.74-11.52 \mathrm{~mm}$. Ib2-AgNPs exerted an inhibitory action against all the five tested pathogenic bacteria while Ib1-AgNPs was inactive against S. aureus ATCC 13565 (Table 2).

\section{Discussion}

Currently, to formulate nanoparticles of specific size and shape, the green methods are used to advance their features. ${ }^{10,27,28}$ During the past few years, rules and regulations for solid waste supervision, and environmental concerns surrounding their disposal have been growing day by day. Thus, the emergence of novel uses of vegetable and fruit wastes, such as their unwanted outer peels, in nanotechnological applications is rising. ${ }^{29-31}$ Nanotechnology is rapidly growing and utilized in a broad array of applications

Table I IC 50 values of antioxidant and antidiabetic assays

\begin{tabular}{|l|l|l|l|}
\hline & Parameters & IC $_{\mathbf{5 0}}$ value $(\boldsymbol{\mu g} / \mathbf{m L})$ lb I & IC $_{\mathbf{5 0}}$ value $(\boldsymbol{\mu g} / \mathbf{m L})$ lb2 \\
\hline Antioxidant assay & DPPH & 120.14 & 107.46 \\
& ABTS & 327.41 & 323.12 \\
& NOx & 389.54 & 291.96 \\
Antidiabetic assay & Reducing $\left(I_{0.5}\right.$ value $)$ & 430.09 & 363.80 \\
& $\alpha$-glucosidase & 0.36 & 0.77 \\
\hline
\end{tabular}


A

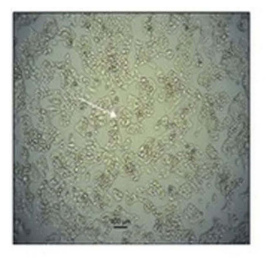

Control
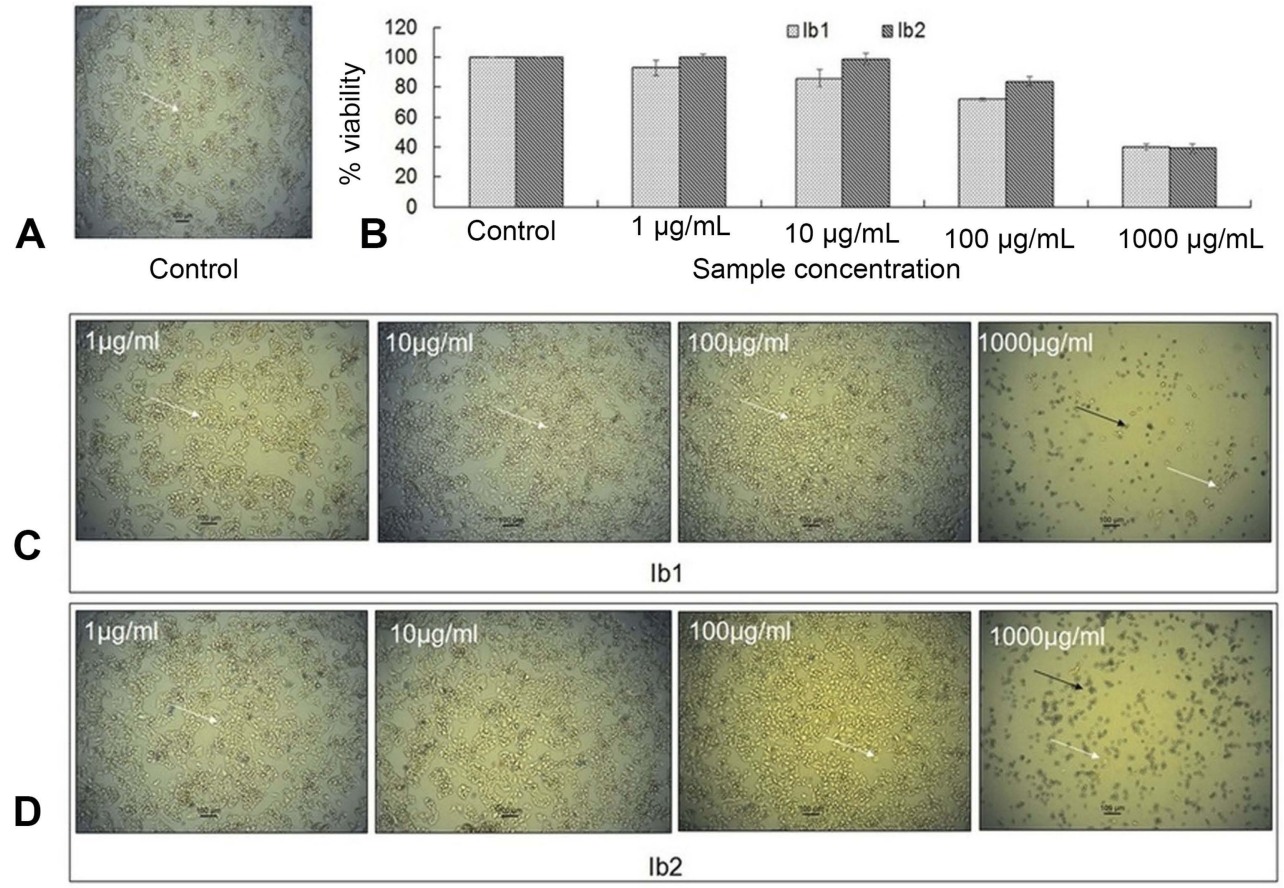

Figure 6 Cytotoxicity of lbl-AgNPs and lb2-AgNPs in HepG2 cancer cells. (A) Control. (B) HepG2 cell viability treated with AgNPs for 24 h. (C, D) Black arrow indicates dead cells, and white arrow indicates live cells $(\mathbf{C}, \mathbf{D})$.

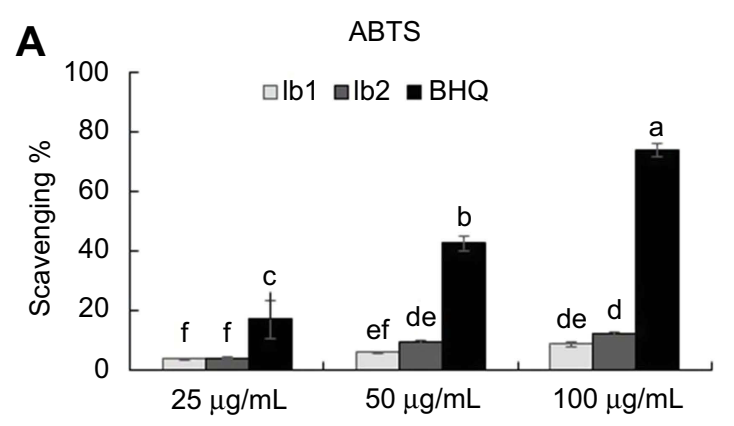

Sample concentration

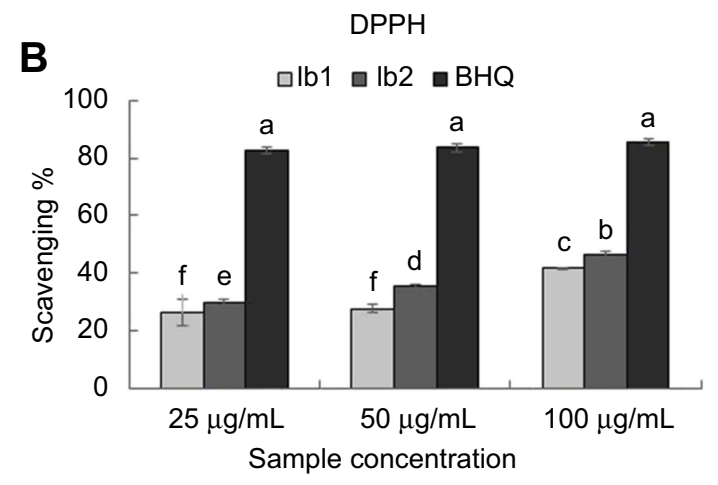

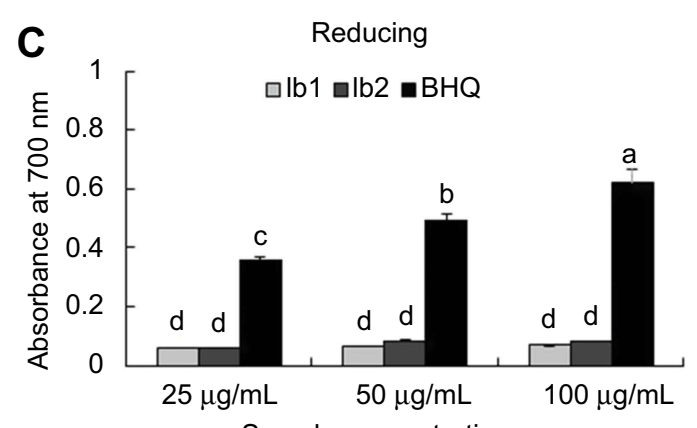

Sample concentration

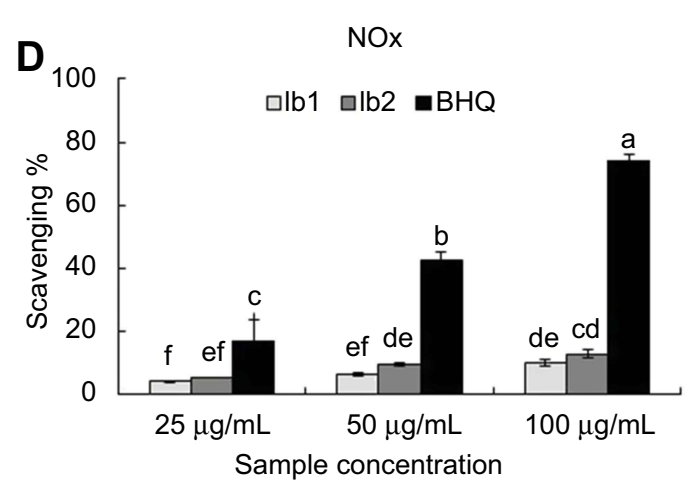

Figure 7 Antioxidant potential of the biosynthesized IbI-AgNPs and lb2-AgNPs. (A) ABTS radical scavenging activity. (B) DPPH-free radical scavenging activity. (C) Reducing power assay. (D) NOx scavenging activity. Difference in the superscript letters indicate statistical significance at $P<0.05$.

in the agriculture, biomedical (drug delivery, tissue scaffolds, wound dressing) and food industries, among others. $^{10,31-33}$ In the arena of nanotechnology, AgNPs have shown impressive performance and are utmost studied among several notable inorganic metal nanoparticles. ${ }^{10,32,34}$ AgNPs display high antimicrobial efficacy and are nontoxic 
Table 2 Antibacterial potential of the biosynthesized lbl \& lb2-AgNPs against pathogenic bacteria

\begin{tabular}{|l|l|l|}
\hline Pathogenic bacteria & lb I-AgNPs* & lb I-AgNPs* \\
\hline Enterococcus feacium DBOI & $09.75^{\mathrm{c}} \pm 0.0 .01^{* *}$ & $09.58^{\mathrm{c}} \pm 0.0 .53$ \\
Salmonella enteritica KCCM II806 & $10.56^{\mathrm{b}} \pm 0.34$ & $11.52^{\mathrm{a}} \pm 0.0 .12$ \\
Listeria monocytogenes ATCC I9III & $11.23^{\mathrm{a}} \pm 0.29$ & $10.43^{\mathrm{b}} \pm 0.0 .37$ \\
Bacillus cereus KCTC 3624 & $10.56^{\mathrm{b}} \pm 0.18$ & $08.74^{\mathrm{d}} \pm 0.0 .20$ \\
Staphylococcus aureus ATCC I3565 & $00.00^{\mathrm{e}} \pm 0.00$ & $09.32^{\mathrm{c}} \pm 0.0 .47$ \\
\hline
\end{tabular}

Notes: *Inhibition zone in $\mathrm{mm}$; **values with different superscript are significant at $P<0.05$.

in nature. To avoid any destructive environmental impact, the green synthesis approaches of nanoparticles are best, as of the absence of any toxic chemicals during the sample preparation and synthesis processes. ${ }^{35}$

Vegetable and fruit peels are generally waste food products and generated in large quantities by the food and agriculture sectors. Polyphenols is a large class amongst the natural metabolites. It is found in a wide variety of vegetables, fruits and various foods. ${ }^{18}$ Different vegetable and fruit peels comprise a plethora of diverse bioactive compounds, like phenolic compounds, carotenoids, dietary fibers, enzymes, vitamins, flavonoids, natural pigments and antioxidant essential oils. Phytochemicals might be utilized in the health industry for medications and medicines and also in the food sector for the development of functional foods. ${ }^{36-38}$ On the approach to sustainable improvement, utilization of food waste products for the manufacture of various vital bioactive elements is a vital step.

Ib L. Lam. correspond to the family Convolvulaceae. It is enriched with various nutrients, like vitamins, minerals and carbohydrates. It is rich in chlorogenic acid, vitamin $\mathrm{C}$, rutin, quercetin and caffeic acid. ${ }^{39}$ Besides, it is also reported to be utilized as an anti-asthmatic, antidiabetic, antitumor, anti-inflammatory and anti-microbial agent. ${ }^{14,40,41}$

A number of essential primary metabolites such as organic acids, amino acids, sugars, sugar alcohols and health beneficial phytochemicals including phenolic acids, flavonoids, anthocyanins and carotenoids and hydrophilic primary metabolites were identified in various $\mathrm{Ib}$ varieties. ${ }^{13,17,42}$ Due to its health benefits, $I \mathrm{Ib}$ is considered a functional food. ${ }^{14}$ Subsequently, the outer peels of $\mathrm{Ib}$ might be expected to have these same compounds, and these could be credited to the bioreduction and capping of Ib1-AgNPs and Ib2-AgNPs.

Hence, in the current research, the outer peel of two varieties of Korean $\mathrm{Ib}$, which are termed $\mathrm{as} \mathrm{Ib} 1$ and $\mathrm{Ib} 2$ used, for green synthesis of Ib1-AgNPs and Ib2-AgNPs, respectively (Figure 1A). The alteration in color of the reaction-solution evidenced the establishment of Ib1AgNPs and Ib2-AgNPs (Figure 1B). ${ }^{43}$ The Ibplant originates from Central America and southern Mexico. ${ }^{44}$ It is broadly recognized that each plant parts, like the stems, roots, leaves and tubers, comprise essential metabolites, like coumarins, batatins and triterpenes, with distinct functional actions. ${ }^{45-47}$ Indeed, Ib is a tuber vegetable. The peels of Ib are enriched with phenolic compounds, which are associated with almost all health benefits, due to their scavenging (free-radical) prospective. ${ }^{13,48,49}$ The Ib proteins also possess various nutraceutical potentials. The currently named Caiapo Potato Powder is an extract from a sweet potato cultivar promoted as an antidiabetic supplement. ${ }^{50-52}$ The sweet potato peels are abundant in storage proteins, identified as sporamins, which are resistant to simulated gastric digestion and present promising antioxidant and antiproliferative properties. ${ }^{53-56}$ Sporamins function as trypsin inhibitors, also after incubation with pepsin or trypsin.

After biosynthesizing the Ib1-AgNPs and Ib2-AgNPs, the reaction kinetics were monitored by UV-Vis absorption spectroscopy between the wavelength ranges of 340-640 (Ib1) and 280-680 nm (Ib2). Generally, as of the free electrons, AgNPs may display a surface plasmon resonance band at $440-558 \mathrm{~nm} .{ }^{57}$ In our present study, the Ib1-AgNPs and Ib2-AgNPs surface plasmon resonance values were detected at around 458 and $446 \mathrm{~nm}$, respectively (Figure 1C). Similar results have been previously reported for synthesized AgNPs. ${ }^{8,57-59}$ This result suggests that phytochemicals existing in $\mathrm{Ib}^{17}$ peels work as reducing and capping agents.

FT-IR allows the analysis of samples up to $\sim 11 \mathrm{~mm}$ in diameter. ${ }^{60}$ In the current study, FT-IR analysis was accomplished to identify the active bio-molecules in the Ib1 and Ib2 peel extracts accountable for reducing and capping the bioreduced AgNPs. Changes in the functional groups might suggest their involvement in the green synthesis of 
Ib1-AgNPs and Ib2-AgNPS. The FT-IR data (Figure 2) evidenced a variation in peaks with different stretching modes between the Ib1 and Ib2 extracts (Figure 2A and B) in comparison with their corresponding AgNPs (Figure 2C and D). According to the FT-IR analysis, it is probable that the peaks at $3321.40,1634.09$ and $1089.17 \mathrm{~cm}^{-1}$ in $\mathrm{Ib} 1$ extract shifted to $3285.56,1620.66$ and $1017.54 \mathrm{~cm}^{-1}$, respectively, in the Ib1-AgNPs. Similarly, the peaks at $3315.75,1634.03$ and $1087.29 \mathrm{~cm}^{-1}$ in Ib2 extract likely shifted to $3275.54,1630.42$ and $1018.51 \mathrm{~cm}^{-1}$ in $\mathrm{Ib} 2-$ AgNPs. The peaks or points at 3285.56 (Ib1) and 3275.54 $\mathrm{cm}^{-1}$ (Ib2) indicate the presence of $\mathrm{O}-\mathrm{H}$ stretch, $\mathrm{H}$-bonded bonds, which belong to the alcohols, phenols functional group. ${ }^{61,62}$ The peaks at $1620.66(\mathrm{Ib} 1)$ and $1630.42 \mathrm{~cm}^{-1}$ (Ib2) specify the presence of N-H bend and it belongs to the functional group $1^{\circ}$ amines. Similarly, the peaks at 1017.54 $\mathrm{cm}^{-1}$ (Ib1-AgNPs) and $1018.51 \mathrm{~cm}^{-1}$ (Ib2-AgNPs) specify the presence of $\mathrm{C}-\mathrm{O}$ stretch which belongs to the alcohols, carboxylic acids, esters, ethers functional groups ${ }^{61,62}$. The minor change in the bands of Ib1-AgNPs and Ib2-AgNPs could be credited to the decline, stabilization and capping procedures in the course of synthesizing the AgNPs. ${ }^{43}$

Visualization of the AgNPs by SEM revealed the spherical form of the bio-synthesized Ib1-AgNPs and Ib2AgNPs in the nanometer range. The biosynthesized nanoparticles were equally agglomerated (Figure $3 \mathrm{~A}$ and $\mathrm{B}$ ), which may be correlated to the removal of solvent during the synthesis process. ${ }^{5,43}$ The elemental composition identified by EDX verified the existence of oxygen and chlorine in both Ib1-AgNPs and Ib2-AgNPs. This finding might be accredited to the sweet potato outer peels utilized in the green-synthesis process, in which the proteins and flavonoids existing in the sweet potato peel could have participated in the capping of Ib1-AgNPs and Ib2-AgNPs. ${ }^{43}$ The high percentage of Ag noted in the EDX end results evidenced that the particles were mostly AgNPs (Figure 3C and $\mathrm{D}$ ). The XRD analysis exposed three distinct peaks in Ib1-AgNPs and four distinct peaks in Ib2-AgNPs. Figure 4 reveals that the peaks were equivalent to the face-centered cubic (fcc) phase of Ag0 standard (JCPDS Card No. 04-0783). ${ }^{43,63,64}$ Identical values were found in prior studies. ${ }^{43,65}$ The XRD data also affirmed the crystalline type of the bio-synthesized Ib1-AgNPs and Ib2-AgNPs. Besides, some unknown peaks were noticed (Figure 4), which suggest that the crystallization of the bioorganic phase could have happened on the peripheral of the biosynthesized Ib1-AgNPs and Ib2-AgNPs, as mentioned in an earlier article. ${ }^{66}$ After their biosynthesis, the antidiabetic, cytotoxic, antioxidant and antibacterial actions of the Ib1AgNPs and Ib2-AgNPs were accomplished.

To therapeutically decrease hyperglycemia, the carbohydrate-digesting enzymes, such as $\alpha$-glucosidase and $\alpha$-amylase, need to be constrained or inhibited, thereby inhibiting the breakdown of carbohydrates into monosaccharides, which are the main contributors to high blood sugar levels. ${ }^{67,68}$ Thus, to manage diabetes, emerging compounds with an inhibitory potential toward carbohydrate-hydrolyzing enzymes might be advantageous. In the current study, the Ib1-AgNPs and Ib2-AgNPs both displayed promising antidiabetic activity (in a dose-dependent manner). A comparatively higher antidiabetic potential was displayed by the Ib1-AgNPs than Ib2AgNPs in the concentration range of $0.25-1.00 \mu \mathrm{g} / \mathrm{mL}$ (Figure 5). More than $97 \%$ inhibition of $\alpha$-glucosidase by the Ib1-AgNPs at $1.00 \mu \mathrm{g} / \mathrm{mL}$ was observed while the Ib2-AgNPs exhibited nearly $65 \%$ inhibition of $\alpha$-glucosidase at the same concentration (Figure 5). Analogous results for AgNPs against $\alpha$-glucosidase have been stated in the research literature ${ }^{69-71}$ The significant potential of both Ib1-AgNPs and Ib2-AgNPs seen in the current research as evident from its significantly less $\mathrm{IC}_{50}$ values (Table 1) is an inspiring sign of their effectiveness in the formulation of active drugs for the management of diabetes.

Cancer is an unusual disorder leading to the wild cell division and damages the body tissues. The structural features of NPs make them outstanding approach for targeting the unusual cell growth instigated by cancer. ${ }^{34}$ Nano-based medicines are highly effective for the diagnosis and treatment of cancer and related diseases. ${ }^{10}$ When the anticancer activity was studied, both the Ib1-AgNPs and Ib2-AgNPs showed high cytotoxicity potential against the HepG2 cell line (Figure 6). In the validation of cytotoxic potential, it was noticed that both AgNPs displayed a high level of cytotoxic potential against the cancer cells, but the AgNPs of Ib2 were more active than the Ib1-AgNPs at low concentrations $(1,10$ and $100 \mu \mathrm{g} / \mathrm{mL}$ ). Moreover, it was detected that as the concentration of AgNPs increased, the anticancer potential increased (Figure 6). The current result is similar with a previously reported result. ${ }^{10,22,72}$

The cytotoxicity potential of Ib1-AgNPs and Ib2AgNPs can be credited to the initiation of intracellular oxidative stress. ${ }^{22,26}$ According to the earlier studies, the cytotoxicity activity of Ib1-AgNPs and Ib2-AgNPs might be the end result of oxidative stress induced in the cells rather than the toxic effect of $\mathrm{Ag}^{+}$ions. ${ }^{22,26,73-79}$

The bio-synthesized Ib1-AgNPs and Ib2-AgNPs exhibited moderate ABTS, DPPH and NOx scavenging activities 
(Figure 7, Table 1). These results might arise from the interference of several functional groups existing in the $\mathrm{Ib} 1$ and Ib2 extracts, which might have played a vital part in the capping and stabilization procedure during Ib1AgNPs and Ib2-AgNPs synthesis. ${ }^{22,72,80}$ The Ib1-AgNPs and Ib2-AgNPs showed higher scavenging effect against DPPH-free radicals in comparison to ABTS radical cations, as evident from less $\mathrm{IC}_{50}$ values (Table 1), which is consistent with previous reports. ${ }^{22,72,81}$ However, Ib2-AgNPs demonstrated slightly more potent antioxidant potential than the Ib1-AgNPs in entire four assays (Table 1), which may be related with the combination of additional oxidants on the external surface area of Ib2-AgNPs. ${ }^{22,43,72}$ The reducing power of Ib1-AgNPs and Ib2-AgNPs may possibly be due to the presence of functional groups on the external surface of the particles (Figure 7C). NOx is an essential bioregulatory molecule in the immune, nervous and cardiovascular systems. ${ }^{22,71,72}$ In the present study, the biosynthesized Ib1-AgNPs and Ib2-AgNPs displayed a concentration-dependent radical scavenging potential (Figure 7C). The relationships between AgNPs and NOx under anhydrous, anaerobic conditions and at room temperature help acceptance of electron from AgNPs. ${ }^{71}$ However, the Ib1-AgNPs and Ib2-AgNPs showed moderate NOx scavenging activity (Figure 7D), which might be due to the difference in the reaction mechanism.

Currently, the growth rate of multidrug-resistant pathogens is widespread, which may have an antagonistic effect on human well-being. ${ }^{82,83}$ Here, the Ib1-AgNPs and Ib2AgNPs exhibited positive antibacterial activity against four pathogenic Gram-positive bacteria and one pathogenic Gram-negative bacteria (Table 2), corroborating previous reports. $9,71,79$ The positive results are credited to the lesser size of the AgNPs, which may facilitate their entry into the bacterial cell walls, in turn, causing damage to bacterial proteins that eventually results in the cell demise of the bacteria. ${ }^{84}$ The inhibition zone might be due to the better diffusion of nanoparticles by diffusion of $\mathrm{Ag}^{+}$ions in the nutrient media. ${ }^{10}$

\section{Conclusion}

The Ib1-AgNPs and Ib2-AgNPs were biosynthesized successfully using the outer peels of two Ib varieties. Both the Ib-AgNPs displayed significant antidiabetic and cytotoxicity activities. Similarly, both the AgNPs exhibited moderate free-radical scavenging and antibacterial activity. Considering all the biological activities tested, the Ib2AgNPs were considered as the most effective AgNPs, which might be credited to the greater richness of bioactive compounds present in Ib2 peel extract. Based on the findings, both the biosynthesized AgNPs could be utilized as promising candidates in various fields such as in the treatment of several diseases like diabetes, cancer, antibacterial wound dressing and for food preservation. The current supporting results might offer a harmless begin for utilization of eco-friendly silver NPs in the pharmaceutical industries.

\section{Ethics approval and informed consent}

Not applicable.

\section{Consent for publication}

Not applicable.

\section{Data availability}

All data generated or analyzed during this study are included in this manuscript.

\section{Abbreviation list}

Ib1, Korean red skin Ipomoea batatas; Ib2, Korean pumpkin Ipomoea batatas; NPs, Nano-particles.

\section{Acknowledgments}

G Das, JK Patra, and HS Shin are grateful to Dongguk University-Seoul, Republic of Korea, for their support. This work was supported by Korea Institute of Planning and Evaluation for Technology in Food, Agriculture, Forestry and Fisheries (IPET) through High Value-added Food Technology Development Program funded by Ministry of Agriculture, Food and Rural Affairs (MAFRA)(118056-2) and funded by Korea Environmental Industry \& Technology Institute (A11700197-0703-0). The authors also wish to thank Prof. Hojun Kim and Dr. AbuZar Ansari of the Department of Rehabilitation Medicine of Korean Medicine, Dongguk University, Goyang, Republic of Korea, for their help in cytotoxicity analysis. CN Vishnuprasad is grateful for the support provided by the TDU, Bengaluru, India. The authors also acknowledge the technical help received from Ms. Ashwini Elango, a Research Fellow from TDU, Bengaluru, India.

\section{Disclosure}

The authors declare there are no competing interests in this work. 


\section{References}

1. Singh K, Panghal M, Kadyan S, Chaudhary U, Yadav JP. Green silver nanoparticles of phyllanthus amarus: as an antibacterial agent against multi drug resistant clinical isolates of pseudomonas aeruginosa. $J$ Nanobiotechnology. 2014;12(1):40. doi:10.1186/s12951-014-0040-x

2. Duman F, Ocsoy I, Kup FO. Chamomile flower extract-directed $\mathrm{CuO}$ nanoparticle formation for its antioxidant and DNA cleavage properties. Mater Sci Eng. 2016;60:333-338. doi:10.1016/j.msec.2015.11.052

3. de Barros CHN, Cruz GCF, Mayrink W, Tasic L. Bio-based synthesis of silver nanoparticles from orange waste: effects of distinct biomolecule coatings on size, morphology, and antimicrobial activity. Nanotechnol Sci Appl. 2018;11:1. doi:10.2147/NSA.S156115

4. Swathy B. A review on metallic silver nanoparticles. IOSR J Pharm. 2014;4(7):2250-3013.

5. Patra JK, Baek K-H. Comparative study of proteasome inhibitory, synergistic antibacterial, synergistic anticandidal, and antioxidant activities of gold nanoparticles biosynthesized using fruit waste materials. Int J Nanomedicine. 2016;11:4691. doi:10.2147/IJN.S108920

6. Yu D, Yam V-W-W. Hydrothermal-induced assembly of colloidal silver spheres into various nanoparticles on the basis of HTABmodified silver mirror reaction. $J$ Phys Chem B. 2005;109 (12):5497-5503.

7. Pugazhendhi A, Prabakar D, Jacob JM, Karuppusamy I, Saratale RG. Synthesis and characterization of silver nanoparticles using Gelidium amansii and its antimicrobial property against various pathogenic bacteria. Microb Pathog. 2018;114:41-45.

8. Saravanan M, Arokiyaraj S, Lakshmi T, Pugazhendhi A. Synthesis of silver nanoparticles from phenerochaete chrysosporium (MTCC-787) and their antibacterial activity against human pathogenic bacteria. Microb Pathog. 2018;117:68-72.

9. Saravanan M, Barik SK, MubarakAli D, Prakash P, Pugazhendhi A. Synthesis of silver nanoparticles from bacillus brevis (NCIM 2533) and their antibacterial activity against pathogenic bacteria. Microb Pathog. 2018;116:221-226.

10. Oves M, Aslam M, Rauf MA, et al. Antimicrobial and anticancer activities of silver nanoparticles synthesized from the root hair extract of Phoenix dactylifera. Mater Sci Eng. 2018;89:429-443.

11. Islam S. Nutritional and Medicinal Qualities of Sweetpotato Tops and Leaves. Cooperative Extension Service, University of Arkansas; Fayetteville, Arkansas; 2014.

12. Mohanraj R, Sivasankar S. Sweet potato (Ipomoea batatas [L.] Lam)A valuable medicinal food: a review. J Med Food. 2014;17(7):733741. doi:10.1089/jmf.2013.2818

13. Anastácio A, Silva R, Carvalho IS. Phenolics extraction from sweet potato peels: modelling and optimization by response surface modelling and artificial neural network. J Food Sci Technol. 2016;53 (12):4117-4125. doi:10.1007/s13197-016-2354-1

14. Ayeleso TB, Ramachela K, Mukwevho E. A review of therapeutic potentials of sweet potato: pharmacological activities and influence of the cultivar. Trop J Pharm Res. 2016;15(12):2751-2761. doi:10.4314/ tjpr.v15i12.31

15. Maria D, Rodica S. Researches on the sweet potato (Ipomea batatas L.) behaviour under the soil and climatic conditions of the SouthWest of Romania. J Hortic For Biotechnol. 2015;19(1):79-84.

16. Xu Y, Cartier A, Porter A, et al. Bioactive compounds and biological activity of extracts from virginia-grown sweet potatoes affected by different cooking methods. J Food Meas Charact. 2018;12(4):25912597. doi:10.1007/s11694-018-9876-3

17. Park S-Y, Lee SY, Yang JW, et al. Comparative analysis of phytochemicals and polar metabolites from colored sweet potato (Ipomoea batatas L.) tubers. Food Sci Biotechnol. 2016;25(1):283-291. doi:10.1007/s10068-016-0041-7
18. Frond AD, Iuhas CI, Stirbu I, et al. Phytochemical characterization of five edible purple-reddish vegetables: anthocyanins, flavonoids, and phenolic acid derivatives. Molecules. 2019;24(8):1536. doi:10.3390/ molecules 24081536

19. Ghosh P, Fawcett D, Sharma S, Poinern G. Production of high-value nanoparticles via biogenic processes using aquacultural and horticultural food waste. Materials. 2017;10(8):852. doi:10.3390/ma10080852

20. Patra JK, Baek K-H. Novel green synthesis of gold nanoparticles using citrullus lanatus rind and investigation of proteasome inhibitory activity, antibacterial, and antioxidant potential. Int J Nanomedicine. 2015; $10: 7253$.

21. Basavegowda N, Idhayadhulla A, Lee YR. Phyto-synthesis of gold nanoparticles using fruit extract of Hovenia dulcis and their biological activities. Ind Crops Prod. 2014;52:745-751. doi:10.1016/j. indcrop.2013.12.006

22. Patra JK, Das G, Kumar A, Ansari A, Kim H, Shin H-S. Photo-mediated biosynthesis of silver nanoparticles using the non-edible accrescent fruiting calyx of physalis peruviana $\mathrm{L}$. fruits and investigation of its radical scavenging potential and cytotoxicity activities. $J$ Photochem Photobiol B. 2018;188:116-125. doi:10.1016/j.jphotobiol.2018.08.004

23. Butala MA, Kukkupuni SK, Venkatasubramanian P, Vishnuprasad $\mathrm{CN}$. An ayurvedic anti-diabetic formulation made from curcuma longa $\mathrm{L}$. and emblica officinalis $\mathrm{L}$. Inhibits $\alpha$-Amylase, $\alpha$ Glucosidase, and starch digestion, in vitro. Starch-Stärke. 2018;70 (5-6):1700182. doi:10.1002/star.201700182

24. Naqvi SZH, Kiran U, Ali MI, et al. Combined efficacy of biologically synthesized silver nanoparticles and different antibiotics against multidrug-resistant bacteria. Int $J$ Nanomedicine. 2013;8:3187. doi:10.2147/IJN.S37465

25. Das G, Park S, Baek K-H. Diversity of endophytic bacteria in a fern species dryopteris uniformis (makino) makino and evaluation of their antibacterial potential against five foodborne pathogenic bacteria. Foodborne Pathog Dis. 2017;14(5):260-268. doi:10.1089/ fpd.2016.2243

26. Faedmaleki F, Shirazi FH, Salarian -A-A, Ashtiani HA, Rastegar H. Toxicity effect of silver nanoparticles on mice liver primary cell culture and HepG2 cell line. Iran J Pharm Res. 2014;13(1):235.

27. Sharma D, Kanchi S, Bisetty K. Biogenic synthesis of nanoparticles: a review. Arabian J Chem. 2015. doi:10.1016/j.arabjc.2015.11.002

28. Roy A, Bulut O, Some S, Mandal AK, Yilmaz MD. Green synthesis of silver nanoparticles: biomolecule-nanoparticle organizations targeting antimicrobial activity. RSC Adv. 2019;9(5):2673-2702. doi:10.1039/C8RA08982E

29. Ahmed S, Ahmad M, Swami BL, Ikram S. A review on plants extract mediated synthesis of silver nanoparticles for antimicrobial applications: a green expertise. $J$ Adv Res. 2016;7(1):17-28. doi:10.1016/j. jare.2015.02.007

30. Reenaa M, Menon AS. Synthesis of silver nanoparticles from different citrus fruit peel extracts and a comparative analysis on its antibacterial activity. Int J Curr Microbiol Applied Sci. 2017;6:23582365. doi:10.20546/ijcmas

31. Omran BA, Nassar HN, Fatthallah NA, Hamdy A, El-Shatoury EH, El-Gendy NS. Waste upcycling of citrus sinensis peels as a green route for the synthesis of silver nanoparticles. Energy Sources Part A. 2018;40(2):227-236. doi:10.1080/15567036.2017.1410597

32. Burdușel A-C, Gherasim O, Grumezescu A, Mogoantă L, Ficai A, Andronescu E. Biomedical applications of silver nanoparticles: an up-todate overview. Nanomaterials. 2018;8(9):681. doi:10.3390/nano8090681

33. Fernando S, Gunasekara T, Holton J. Antimicrobial nanoparticles: applications and mechanisms of action. Sri Lankan J Infect Dis. 2018;8:1. doi:10.4038/sljid.v8i1.8167

34. Pugazhendhi A, Edison TNJI, Karuppusamy I, Kathirvel B. Inorganic nanoparticles: a potential cancer therapy for human welfare. Int $J$ Pharm. 2018;539(1-2):104-111. doi:10.1016/j.ijpharm.2018.01.034 
35. Siddiqi KS, Husen A, Rao RA. A review on biosynthesis of silver nanoparticles and their biocidal properties. J Nanobiotechnology. 2018;16(1):14.

36. Rafiq S, Kaul R, Sofi S, Bashir N, Nazir F, Nayik GA. Citrus peel as a source of functional ingredient: a review. J Saudi Soc Agric Sci. 2018;17(4):351-358. doi:10.1016/j.jssas.2016.07.006

37. Rehan M, Abdel-Wahed NA, Farouk A, El-Zawahry MM. Extraction of valuable compounds from orange peel waste for advanced functionalization of cellulosic surfaces. ACS Sustainable Chem Eng. 2018;6(5):5911-5928. doi:10.1021/acssuschemeng.7b04302

38. Sagar NA, Pareek S, Sharma S, Yahia EM, Lobo MG. Fruit and vegetable waste: bioactive compounds, their extraction, and possible utilization. Compr Rev Food Sci Food Saf. 2018;17(3):512-531. doi:10.1111/crf3.2018.17.issue-3

39. Guan Y, Wu T, Lin M, Ye J. Determination of pharmacologically active ingredients in sweet potato (Ipomoea batatas L.) by capillary electrophoresis with electrochemical detection. J Agric Food Chem. 2006;54(1):24-28. doi:10.1021/jf0508347

40. Meva F, Segnou ML, Ebongue CO, et al. Unexplored vegetal green synthesis of silver nanoparticles: A preliminary study with corchorus olitorus linn and ipomea batatas (L.) Lam. Afr J Biochem. 2016;15 (10):341-349. doi:10.5897/AJB2015.14962

41. Majid M, Nasir B, Zahra SS, Khan MR, Mirza B, Haq I-U. Ipomoea batatas L. Lam. ameliorates acute and chronic inflammations by suppressing inflammatory mediators, a comprehensive exploration using in vitro and in vivo models. BMC Complement Altern Med. 2018;18(1):216. doi:10.1186/s12906-018-2317-3

42. de Albuquerque TMR, Sampaio KB, de Souza EL. Sweet potato roots: unrevealing an old food as a source of health promoting bioactive compounds - A review. Trends Food Sci Technol. 2019;85:277-286. doi:10.1016/j.tifs.2018.11.006

43. He Y, Wei F, Ma Z, et al. Green synthesis of silver nanoparticles using seed extract of Alpinia katsumadai, and their antioxidant, cytotoxicity, and antibacterial activities. RSC Adv. 2017;7 (63):39842-39851. doi:10.1039/C7RA05286C

44. Woolfe JA. Sweet Potato: An Untapped Food Resource. Cambridge University Press; Cambridge, United Kingdom; 1992.

45. Escalante-Sánchez E, Pereda-Miranda R. Batatins I and II, ester-type dimers of acylated pentasaccharides from the resin glycosides of sweet potato. J Nat Prod. 2007;70(6):1029-1034. doi:10.1021/np070093z

46. Muyinza H, Stevenson PC, Talwana H, Hall D, Farman DI, Mwanga RO. Root Chemicals Could Offer Opportunities for Breeding for Sweet Potato Resistance to the Weevil Cylas Puncticollis Boheman (Coleoptera: Apionidae). In: Midiwo J, Clough J, editors. Aspects of African Biodiversity Proceedings of the Pan Africa Chemistry Network Biodiversity Conference, Nairobi, Sept 2008. London: Royal Society of Chemistry Publishing; Cambridge, United Kingdom; p.49-57; 2009.

47. Yuan J-M, Koh W-P, Murphy SE, et al. Urinary levels of tobaccospecific nitrosamine metabolites in relation to lung cancer development in two prospective cohorts of cigarette smokers. Cancer Res. 2009;69(7):2990-2995. doi:10.1158/0008-5472.CAN-08-4330

48. Zhu F, Cai Y-Z, Yang X, Ke J, Corke H. Anthocyanins, hydroxycinnamic acid derivatives, and antioxidant activity in roots of different Chinese purple-fleshed sweetpotato genotypes. J Agric Food Chem 2010;58(13):7588-7596. doi:10.1021/jf101867t

49. Panda V, Sonkamble M, Patil S. Wound healing activity of Ipomoea batatas tubers (sweet potato). Funct Foods Health Dis. 2011;1 (10):403-415. doi:10.31989/ffhd.v1i10.118

50. Ludvik B, Waldhäusl W, Prager R, Kautzky-Willer A, Pacini G. Mode of action of ipomoea batatas (Caiapo) in type 2 diabetic patients. Metabolism. 2003;52(7):875-880.

51. Ludvik B, Neuffer B, Pacini G. Efficacy of ipomoea batatas (Caiapo) on diabetes control in type 2 diabetic subjects treated with diet. Diabetes Care. 2004;27(2):436-440. doi:10.2337/ diacare.27.2.436
52. Kusano S, Tamasu S, Nakatsugawa S. Effects of the white-skinned sweet potato (Ipomoea batata L.) on the expression of adipocytokine in adipose tissue of genetic type 2 diabetic mice. Food Sci Technol Res. 2005;11(4):369-372. doi:10.3136/fstr.11.369

53. Hou W-C, Han C-H, Chen H-J, Wen C-L, Lin Y-H. Storage proteins of two cultivars of sweet potato (Ipomoea batatas L.) and their protease hydrolysates exhibited antioxidant activity in vitro. Plant Sci. 2005;168(2):449-456. doi:10.1016/j.plantsci.2004.09.008

54. Huang G-J, Sheu M-J, Chen H-J, Chang Y-S, Lin Y-H. Growth inhibition and induction of apoptosis in NB4 promyelocytic leukemia cells by trypsin inhibitor from sweet potato storage roots. J Agric Food Chem. 2007;55(7):2548-2553. doi:10.1021/jf063008m

55. Huang GJ, Chang HY, Chen HJ, et al. Effects of trypsin inhibitor on plasma antioxidant activity and lipid levels in mice from sweet potato roots. $J$ Sci Food Agric. 2008;88(14):2556-2562. doi:10.1002/jsfa.3390

56. Maloney KP, Truong VD, Allen JC. Susceptibility of sweet potato (Ipomoea batatas) peel proteins to digestive enzymes. Food Sci Nutr. 2014;2(4):351-360. doi:10.1002/fsn3.110

57. Khalil MM, Ismail EH, El-Baghdady KZ, Mohamed D. Green synthesis of silver nanoparticles using olive leaf extract and its antibacterial activity. Arabian J Chem. 2014;7(6):1131-1139.

58. Singh K, Naidoo Y, Mocktar C, Baijnath H. Biosynthesis of silver nanoparticles using Plumbago auriculata leaf and calyx extracts and evaluation of their antimicrobial activities. Adv Nat Sci. 2018;9 (3):035004.

59. Ashraf JM, Ansari MA, Khan HM, Alzohairy MA, Choi I. Green synthesis of silver nanoparticles and characterization of their inhibitory effects on AGEs formation using biophysical techniques. Sci Rep. 2016;6:20414.

60. Devaraj P, Kumari P, Aarti C, Renganathan A. Synthesis and characterization of silver nanoparticles using cannonball leaves and their cytotoxic activity against MCF-7 cell line. J Nanotechnol. 2013; 2013; http://dx.doi.org/10.1155/2013/598328.

61. Kalaiyarasu T, Karthi N, Sharmila GV, Manju V. In vitro assessment of antioxidant and antibacterial activity of green synthesized silver nanoparticles from digitaria radicosa leaves. Asian J Pharm Clin Res. 2016;9:1.

62. Coates J. Interpretation of Infrared Spectra, a Practical Approach. In: Meyers (Ed.) Encyclopedia of Analytical Chemistry. John Wiley \& Sons Ltd, Chichester, 2000.

63. Jagtap UB, Bapat VA. Green synthesis of silver nanoparticles using artocarpus heterophyllus Lam. seed extract and its antibacterial activity. Ind Crops Prod. 2013;46:132-137.

64. Basavegowda N, Lee YR. Synthesis of silver nanoparticles using satsuma mandarin (Citrus unshiu) peel extract: a novel approach towards waste utilization. Mater Lett. 2013;109:31-33.

65. He Y, Li X, Zheng Y, et al. A green approach for synthesizing silver nanoparticles, and their antibacterial and cytotoxic activities. New $J$ Chem. 2018;42(4):2882-2888.

66. Vanaja M, Annadurai G. Coleus aromaticus leaf extract mediated synthesis of silver nanoparticles and its bactericidal activity. Appl Nanosci. 2013;3(3):217-223.

67. Etxeberria U, de la Garza AL, Campión J, Martinez JA, Milagro FI. Antidiabetic effects of natural plant extracts via inhibition of carbohydrate hydrolysis enzymes with emphasis on pancreatic alpha amylase. Expert Opin Ther Targets. 2012;16(3):269-297.

68. Nickavar B, Abolhasani L. Bioactivity-guided separation of an $\alpha$ amylase inhibitor flavonoid from Salvia virgata. Iran J Pharm Res. 2013;12(1):57.

69. Balan K, Qing W, Wang Y, et al. Antidiabetic activity of silver nanoparticles from green synthesis using Lonicera japonica leaf extract. RSC Adv. 2016;6(46):40162-40168.

70. Prabhu S, Vinodhini S, Elanchezhiyan C, Rajeswari D. Evaluation of antidiabetic activity of biologically synthesized silver nanoparticles using Pouteria sapota in streptozotocin-induced diabetic rats: 在链艮 霉素 - 诱导的糖尿病大鼠中评估使用山榄果生物合成的银纳米粒 子的降糖活性. J Diabetes. 2018;10(1):28-42. 
71. Govindappa M, Hemashekhar B, Arthikala M-K, Rai VR, Ramachandra Y. Characterization, antibacterial, antioxidant, antidiabetic, anti-inflammatory and antityrosinase activity of green synthesized silver nanoparticles using Calophyllum tomentosum leaves extract. Results Phys. 2018;9:400-408.

72. Rajkumar T, Sapi A, Das G, Debnath T, Ansari A, Patra JK. Biosynthesis of silver nanoparticle using extract of Zea mays (corn flour) and investigation of its cytotoxicity effect and radical scavenging potential. J Photochem Photobiol B. 2019;193:1-7.

73. AshaRani PV, Mun GK, Hande MP, Valiyaveettil S. Cytotoxicity and genotoxicity of silver nanomaterials in Human Cells. ACS Nano. 2009;24(3):279-290.

74. Ahmad A, Syed F, Shah A, et al. Silver and gold nanoparticles from Sargentodoxa cuneata: synthesis, characterization and antileishmanial activity. RSC Adv. 2015;5(90):73793-73806.

75. Sánchez-Navarro M, Ruiz-Torres CA, Niño-Martínez $N$, et al. Cytotoxic and bactericidal effect of silver nanoparticles obtained by green synthesis method using annona muricata aqueous extract and functionalized with 5-fluorouracil. Bioinorg Chem Appl. 2018;2018: 1-8. https://doi.org/10.1155/2018/6506381.

76. Prasannaraj G, Venkatachalam P. Green engineering of biomoleculecoated metallic silver nanoparticles and their potential cytotoxic activity against cancer cell lines. Adv Nat Sci. 2017;8(2):025001.

77. Mousavi B, Tafvizi F, Zaker Bostanabad S. Green synthesis of silver nanoparticles using artemisia turcomanica leaf extract and the study of anti-cancer effect and apoptosis induction on gastric cancer cell line (AGS). Artif Cells Nanomed Biotechnol. 2018;46(Sup 1): 499-510.
78. Wypij M, Czarnecka J, Świecimska M, Dahm H, Rai M, Golinska P. Synthesis, characterization and evaluation of antimicrobial and cytotoxic activities of biogenic silver nanoparticles synthesized from streptomyces xinghaiensis OF1 strain. World $J$ Microbiol Biotechnol. 2018;34(2):23.

79. Patil Shriniwas P. Antioxidant, antibacterial and cytotoxic potential of silver nanoparticles synthesized using terpenes rich extract of Lantana camara L. leaves. Biochem Biophys Rep. 2017;10:76.

80. Adedapo AA, Jimoh FO, Afolayan AJ, Masika PJ. Antioxidant activities and phenolic contents of the methanol extracts of the stems of acokanthera oppositifolia and adenia gummifera. $B M C$ Complement Altern Med. 2008;8(1):54.

81. Otunola GA, Afolayan AJ. In vitro antibacterial, antioxidant and toxicity profile of silver nanoparticles green-synthesized and characterized from aqueous extract of a spice blend formulation. Biotechnol Biotechnol Equip. 2018;32(3):724-733.

82. Rajeshkumar S, Malarkodi C. In vitro antibacterial activity and mechanism of silver nanoparticles against foodborne pathogens. Bioinorg Chem Appl. 2014;2014: 1-10. http://dx.doi.org/10.1155/ 2014/581890.

83. Pugazhendhi A, Kumar SS, Manikandan M, Saravanan M. Photocatalytic properties and antimicrobial efficacy of $\mathrm{Fe}$ doped $\mathrm{CuO}$ nanoparticles against the pathogenic bacteria and fungi. Microb Pathog. 2018;122:84-89.

84. Ramesh P, Kokila T, Geetha D. Plant mediated green synthesis and antibacterial activity of silver nanoparticles using emblica officinalis fruit extract. Spectrochim Acta Part A. 2015;142:339-343.
International Journal of Nanomedicine

\section{Publish your work in this journal}

The International Journal of Nanomedicine is an international, peerreviewed journal focusing on the application of nanotechnology in diagnostics, therapeutics, and drug delivery systems throughout the biomedical field. This journal is indexed on PubMed Central, MedLine, CAS, SciSearch ${ }^{\circledR}$, Current Contents ${ }^{\circledR} /$ Clinical Medicine, $^{-}$
Journal Citation Reports/Science Edition, EMBase, Scopus and the Elsevier Bibliographic databases. The manuscript management system is completely online and includes a very quick and fair peer-review system, which is all easy to use. Visit http://www.dovepress.com/ testimonials.php to read real quotes from published authors. 